\title{
Hargowere \\ Clever outreach or costly diversion? An academic library evaluates its Facebook experience
}

A fter my presentation on "How Rutgers University Libraries Market Their Libraries" at the Academic Libraries Advancement and Development Network (ALADN) conference in Austin, Texas, in early June 2008, I was taking questions. One questioner asked: How would you assess your library's efforts of Facebook?

In retrospect, I don't think I answered the question very well, because I had not systematically thought about the question beforehand. This article is an attempt to address the challenge of carefully evaluating our library system's two-year experience on Facebook and assessing its value to us.

\section{What is Facebook?}

The Washington Post reported in June 2008 that Facebook had surpassed MySpace in reliable measures of popularity, attracting 123.9 million visitors and 50.6 billion page views worldwide in May alone. ${ }^{1}$ Facebook is, of course, enormously popular among college students. It was started in 2004 as a Web site for students at Harvard and quickly elicited the interest of students at other schools. There were 43,000 people registered in the Rutgers University (RU) network on Facebook in September 2006 and 55,000 by July 2008..

Facebook users register for free and create a profile page, which follows a predetermined format. Profile pages provide space for a picture and areas for personal information, such as relationship status and interests, educational status and interests, and favorite music, books, TV shows, movies, and quotes.

Each profile includes a wall where the user or his or her friends can post comments and links to other Web sites, videos, or graphics.
Profiles also allow user s to post photo albums and to send messages to other people who have profiles on Facebook. Once users have a profile page in Facebook, they can "friend" or be "friended" by other Facebook members. The profile pictures and names of a person's Facebook friends appear in a prominent location on their Profile page.

Facebook members can also create or join a Facebook group. Similar to profile pages, group pages include a picture, a wall, contact information, and the opportunity to post photos. But they differ in their focus and function. Group creators assign a description to the group and select administrators. Facebook members "join" a group, and the name of the group appears in a section of their profile page. Group membership serves as a type of online identity bracelet, allowing Facebook members to identify organizations, causes, or interests they support or to learn about their friends' interests in a nonthreatening manner.

\section{How we found our way onto Facebook}

The RU Libraries embarked on our Facebook initiative in the fall 2006 semester. Our interest in Facebook was spurred by a May 2006 article in College $\&$ Research Libraries News, in which Brian Mathews of Georgia Tech (GT) described an initial Facebook experiment at GT. ${ }^{2}$ Further encouragement came from observing student workers in the administration suite, who spent hours each day checking,

Harry Glazer is the communications director of the Rutgers University Libraries in New Jersey, e-mail: hglazer@rci.rutgers.edu

○ 2009 Harry Glazer 
updating, and interacting with their Facebook universe.

Julie Still, a librarian at the Paul Robeson Library at Rutgers-Camden, and I teamed up to launch the RU Libraries' Facebook presence. Still and I posted our own individual profiles, a prerequisite to life in Facebook, and then formed the group Inside Info @ RU Libraries. Then we recruited students to join the group, inviting members of like-minded groups on the Facebook Rutgers' network, student workers in the libraries, students we met on campus, leaders of student government, editors of student papers, and others to join our group. By the beginning of the spring semester, we had more than 120 members of our group.

Our initial goals for the Facebook initiative were simple-to explore the new-to-us medium, test its usefulness as an outlet for sharing news about the RU Libraries, and develop an alternative platform for contacts with students. In that vein, we included the following description on the Inside Info @ RU Libraries profile page:

"Library news. Library happenings. New resources and services that will make your coursework easier and let you find the info you want faster. Find answers to any questions you have about the libraries."

\section{What we've gained}

Shortly after we set up the group, a student posted the following comment on the wall of our group page: "I have a very serious question. Where can I go to get newer, fiction type books. Ex: the new artemis fowl for example or just artemis fowl in general."

I wrote back and told the student about our interlibrary loan service, provided a link to the service, and said she could probably get the book within five-to-seven business days. She wrote back, thanked me for my response, and we never heard from her again.

In the spring of 2007, I experimented with the Facebook group by sending a message to all members, asking them: 1) What was their favorite radio station? 2) What libraries Web page, besides the catalog, did they use recently? And was it helpful? I promised small prizes (a nice brass RU Libraries bookmark) to the fifth, fifteenth, and twenty-fifth responses.

I received 26 replies, representing a 15 percent response rate. I learned that Z100, "New York's hit music station" featuring the best of Madonna, the Jonas Brothers, Pussycat Dolls, and other pop sensations, was the favored radio selection, receiving nearly one-third of the votes. What I learned about the RU Libraries though was far more interesting.

The top answer to the question "What libraries' Web page have you used recently?" receiving five votes, was the student hometown public libraries' Web pages. Our e-reserves pages received four votes, our interlibrary loan and e-journals received three votes, and a dozen other pages on our Web site received one or two votes.

Though I understood that the responses were likely an unrepresentative sample of the student population as a whole, since they were drawn only from a population of 170 people who joined our group on Facebook, I still found the leading answer disconcerting.

In the spring of 2008, I sent out a mass email to all the members of our Facebook group asking for responses to a quick quiz about news posted on the RU Libraries Web site, requesting the name of a librarian or libraries' service that helped them that semester, and offering prizes. The response was decidedly underwhelming - four people wrote back out of about 150 group members.

One of those respondents, however, successfully answered the two questions I posed and included the following comments:

"I was doing research through the Aresty Research Center for Undergraduates this year and the library's resources were amazingly helpful!! I met with two research librarians who were extremely helpful in figuring out where to begin looking for information-Sara Harrington and Kayo Denda. The ILL was extremely helpful in finding some semi-rare books on my narrow research topic. ... I love the resources that the libraries offer!"

I shared the comments with our university librarian and suggested that we include 
the quote in our glossy annual report. She readily agreed.

\section{What also worked, splendidly ... and a qualification}

In the fall 2006 semester I noticed that one of the resources I'd plugged in a very brief posting on our group's wall, a set of music databases, was covered in a front-page story in the Daily Targum, the daily student newspaper. In my experience, a new libraries' database rarely gains coverage in the student newspaper. Rarer still is a front-page story. I wondered if there was a Facebook connection.

The following Friday, the Daily Targum praised the libraries in an editorial for increasing information access at the university for students, despite budget cuts at the university due to decreased state aid. As an example the Daily Targum cited our addition of two new databases to our Web site. The editorial added another reason to praise the RU Libraries: "Furthermore, the library has established a group on Facebook, disseminating news and information regarding the libraries to students in a manner that will reach them more effectively. "

The proximity in the Daily Targum column of praise of our new music databases to mention of our Facebook group appeared to confirm the connection between the two. This apparent connection continued. Early in the spring 2007 semester the Daily Targum ran a story about our instituting extended evening hours, which I traced to an item I posted on our Facebook group's wall. Later that semester, the paper ran a large front-page story focused entirely on the RU Libraries' efforts on Facebook.

I realized weeks later that the very favorable RU Libraries' Facebook group/Daily Targum connection could be attributed to one particular personal connection. In October I'd visited the offices of the newspaper and complimented the editor on the Daily Targum's printed apology for its parody issue, which many, including myself, found unduly crude. The editor looked back at me, her eyes watery, and told me how much she appreciated the feedback because the newspaper's student staff had received a deluge of criticism on the parody.

I spoke with the editor a little while longer and she asked me what new projects the RU Libraries were working on. I mentioned the Facebook initiative, gave her the name of our group, and invited her to visit the page. Within the next week the editor friended me on Facebook and joined the group.

Once someone else becomes my friend on Facebook, they receive an update about me on their Facebook homepage whenever I change something on my profile page or post something on someone else's wall. This "News Feeds" feature, however, does not encompass changes to a group page. But it does report on a posting I place on the group's wall. Piecing all this together, it occurred to me that it was most likely that the Daily Targum began noticing the RU Libraries activity on our Facebook group page after the editor started receiving news feeds when I posted something to the group's wall.

\section{Measuring the value}

The preceding stories demonstrate that an academic library's presence on Facebook can produce worthwhile results. Yet it is hard to predict what those results will be, and sometimes the benefit received differed markedly from what we were initially seeking.

Another "fuzzy" byproduct of our Facebook initiative is that it has provided the impetus for me to initiate conversations with student workers in the RU Libraries and refine my understanding of how to shape news communications to elicit students' interest. For me these conversations, and the resulting improvement in my work, have been one

\section{Online extra}

Visit the January 2009 issue of CERL News online at www.acrl.org/c\&rlnews for a podcast interview with article author Harry Glazer. 
of the most rewarding benefits of the RU Libraries Facebook initiative.

\section{Metrics for the future}

In looking back over the first two years of our Facebook initiative, it is clear that our initial goals were practical and realistic, yet poorly defined. It thus proves difficult to measure the value of the initiative versus the time and the hopes invested. For the coming year I plan to focus our Facebook activity on two measurable goals that should allow us to test the utility of the medium with greater precision and reliability.

One goal of our Facebook activities will be to recruit incoming students to the RU Libraries' Facebook group and to post short items to the group's wall (with links to full news stories) that reflect the interests of this population. Incoming students are a primary target audience of our 2008-09 marketing plan, so this goal dovetails well with the plan. Success can be measured by the number of new members in our Facebook group who are first-year or transfer students, the number of stories posted to the group's wall tailored to their interests, and the number of respondents to a monthly quiz about the postings.

A second goal of our Facebook activities in 2008-09 will focus on rebuilding one of the assets we observed in the first year of the project: relationships with student workers at the student newspaper. I plan to make a special effort in early fall 2008 to recruit reporters, editors, and photographers of the Daily Targum to the RU Libraries' Facebook group. Success can be assessed by the number of new group members who work at the newspaper and the number of newspaper stories printed about the RU Libraries' in 2008-09 that were first promoted on our group's wall.

\section{Still ...}

I'm eager to revise our approach to the Facebook initiative in the next year so we can more reliably measure its effectiveness. I'm mindful, though, that our efforts in this

(continues on page 19)

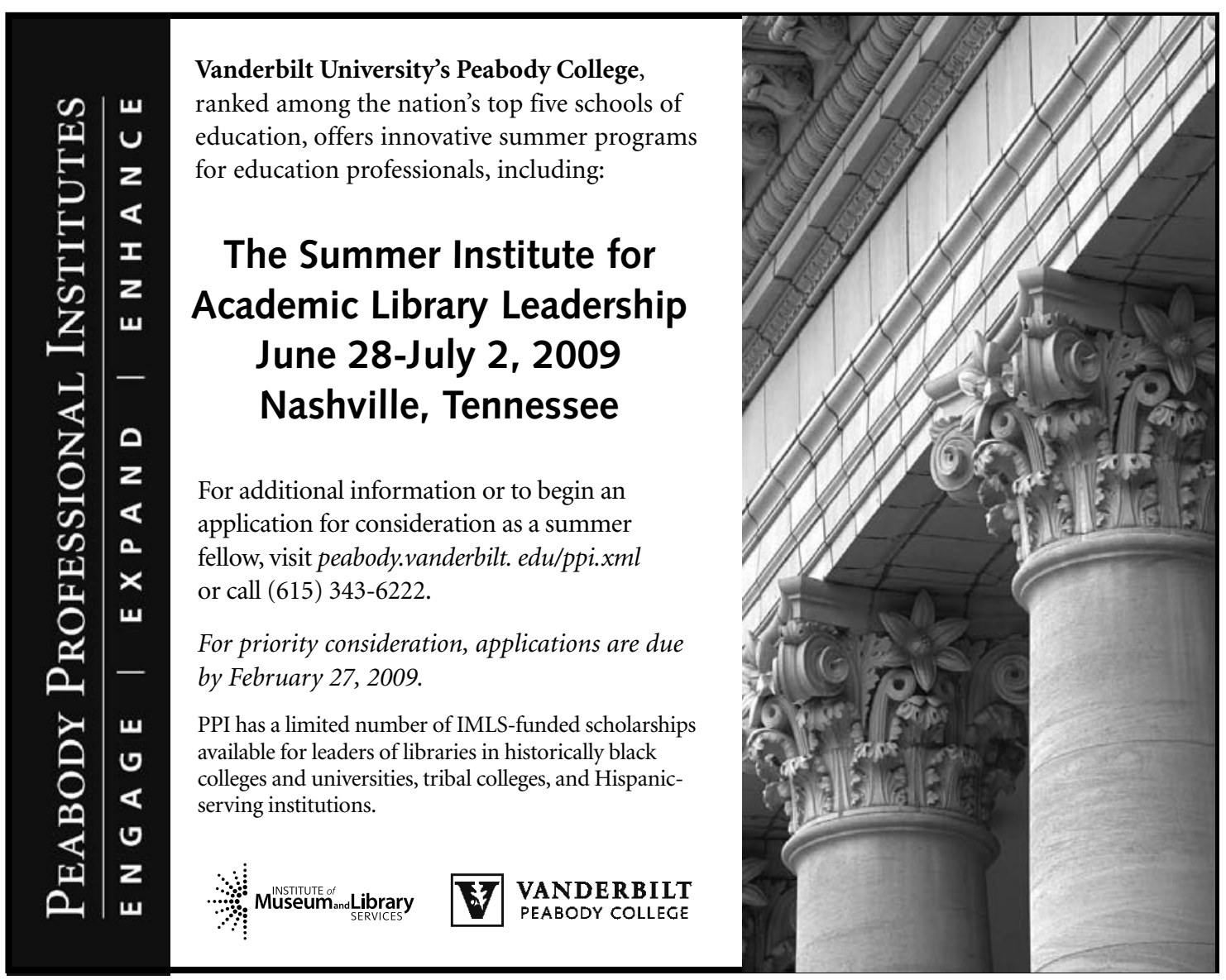


2. These ideas are explored in Stephen Carr, et al., Public space (New York, NY: Cambridge University Press, 1992).

3. Henri Lefebvre, The production of space, trans. Donald Nicholson-Smith (Cambridge, MA: Blackwell, 1992).

4. See www.pps.org/civic_centers/ for links to examples of PPS library projects. In addition, PPS staff participated in a BCLA 2008 pre-conference and are invited speakers at the OLA Super Conference in 2009.

5. Project for Public Spaces, How to turn a place around (New York, NY: Project for Public Spaces, 2002).

6. For relevant examples using observation, questionnaires, and interviews, see Gloria
Leckie and John Hopkins, "The public place of central libraries: Findings from Toronto and Vancouver," Library Quarterly, 72 (2002): 326372. and Howard Silver, "Use of collaborative spaces in an academic library" (PhD diss., Simmons College, 2007), digitalcommons. bryant.edu/library_misc/1

7. Harold Shill and Shawn Tonner, "Creating a better place: Physical improvements in academic libraries, 1995 - 2002," College \& Research Libraries, 64 (2003): 431-66.

8. Lyman Ross and Pongracz Sennyey, "The library is dead, long live the library! The practice of academic librarianship and the digital revolution," The Journal of Academic Librarianship, 34 (2008): 145-52. n
("Clever outreach..." cont. from page 14) medium, and our attempts to assess their value, are still a "work in progress." I believe that the value of immersing in a medium strongly favored by students, and becoming more familiar with their styles of engagement, is difficult to fully or fairly evaluate. We've learned that Facebook activities can lead to useful information about students' preferences, positive press coverage, terrific testimonials, and rewarding extensions of established relationships. These benefits, though prized, are not predictable.

Facebook is worth more to us than those rewards. Our work on Facebook opens the door for us to the conversations, diversions, attitudes, and social habits of one of our critical audiences. To serve this group well, it helps to understand them as best we can. $\boldsymbol{n}$

\title{
University of Oklahoma Libraries presents
}

\section{Redefining Relevance: \\ Exceeding User Expectations in a Digital Age}

\author{
March 5-6, 2009 \\ Oklahoma City, Oklahoma \\ Speakers:
}

\begin{abstract}
Barbara I. Dewey - University of Tennessee Libraries Ronald G. Dunn - Cengage Learning Brinley Franklin - University of Connecticut Libraries Fred Heath - University of Texas Libraries Anne Kenney - Cornell University Library James G. Neal - Columbia University Libraries Bernard F. Reilly - Center for Research Libraries Carton Rogers - University of Pennsylvania Library
\end{abstract}

\section{http://libraries.ou.edu/conference}

REGISTRATION DEADLINE: February 13, 2009

Contact for Information: Rhonda Cannon, University of Oklahoma Libraries, Norman, OK 73019; rhondacannon@ou.edu;

Phone: 405-325-2611 